\title{
Bacteria of an anaerobic 1,2-dichloropropane- dechlorinating mixed culture are phylogenetically related to those of other anaerobic dechlorinating consortia
}

\author{
Cord Schlötelburg, ${ }^{1}$ Friedrich von Wintzingerode, ${ }^{1}$ Regine Hauck, ${ }^{2}$ \\ Werner Hegemann ${ }^{2}$ and Ulf B. Göbel ${ }^{1}$
}

\footnotetext{
1 Institut für Mikrobiologie und Hygiene, Universitätsklinikum Charité, HumboldtUniversität zu Berlin Dorotheenstrasse 96, 10117 Berlin, Germany

2 Institut für Technischen Umweltschutz, Technische Universität Berlin, Strasse des 17. Juni 135, 10623 Berlin, Germany
}

\author{
Author for correspondence: Ulf B. Göbel. Tel: +49 302093 4715. Fax: +49 3020934703. \\ e-mail: ulf.goebel@charite.de
}

\begin{abstract}
A 16S-rDNA-based molecular study was performed to determine the bacterial diversity of an anaerobic, 1,2-dichloropropane-dechlorinating bioreactor consortium derived from sediment of the River Saale, Germany. Total community DNA was extracted and bacterial 16S rRNA genes were subsequently amplified using conserved primers. A clone library was constructed and analysed by sequencing the 16S rDNA inserts of randomly chosen clones followed by dot blot hybridization with labelled polynucleotide probes. The phylogenetic analysis revealed significant sequence similarities of several as yet uncultured bacterial species in the bioreactor to those found in other reductively dechlorinating freshwater consortia. In contrast, no close relationship was obtained with as yet uncultured bacteria found in reductively dechlorinating consortia derived from marine habitats. One rDNA clone showed $>\mathbf{9 7} \%$ sequence similarity to Dehalobacter species, known for reductive dechlorination of tri- and tetrachloroethene. These results suggest that reductive dechlorination in microbial freshwater habitats depends upon a specific bacterial community structure.
\end{abstract}

Keywords: 16S rDNA clone library, bacterial diversity, 1,2-dichloropropane, reductive dechlorination, Dehalobacter

\section{INTRODUCTION}

Halogenated propanes, including 1,2-dichloropropane (DCP), are toxic and carcinogenic compounds which in the past have been used extensively as fumigants for a variety of crops (Löffler et al., 1997). DCP is still used as a solvent, oil and paraffin extractant, metaldegreasing agent, paint and furniture finish remover, lead scavenger in antiknock fluids and textile stain remover. During the production of chlorinated compounds, such as carbon tetrachloride and tetrachloroethene, DCP is used as a chemical intermediate. Additionally, it is formed as a by-product during the synthesis of propyleneoxide and epichlorohydrine

Abbreviations: DCP, 1,2-dichloropropane; DIG, digoxigenin; SHA, Saale, Halle, library A.

The GenBank accession numbers for the 16S rDNA SHA sequences are AJ249094-AJ249114.
(Hegemann et al., 1998). In Germany, 78000 tons of DCP per year are produced. DCP is only moderately soluble in aqueous systems and is slowly degraded by micro-organisms in natural habitats.

Under aerobic conditions partial microbial conversion of DCP by methanotrophic and nitrifying bacteria utilizing DCP co-metabolically has been reported by Oldenhuis et al. (1989) and Rasche et al. (1990). As shown by Vandenbergh \& Kunka (1988), Pseudomonas fluorescens PFL12 is able to grow aerobically in the presence of DCP as the only available carbon and energy source. However, DCP degradation products have not been detected. So far, complete dehalogenation of DCP to propene has only been reported for anaerobic microbial consortia enriched from freshwater sediments, which degrade DCP by reductive dechlorination (Löffler et al., 1997). In our laboratory we have investigated the continuous anaerobic dechlorination of DCP in a fluidized bed bioreactor 
using a mixed microbial enrichment culture derived from sediment of the River Saale, Germany, as a first step towards a technical application of this process (Hauck et al., 1999).

The efficient technical use of complex microbial communities is often hampered by their unknown population structure. The determination of microbial diversity is hence an important prerequisite for the bioremediation of DCP-polluted sites and wastewater streams. Conventional culture-based analyses of complex microbiota are strongly biased (Head et al., 1998). Therefore, a direct culture-independent approach based on in vitro amplification of $16 \mathrm{~S}$ rRNA genes has been chosen. The occurrence of $16 \mathrm{~S}$ rDNA sequences closely related to cultivated dechlorinating bacteria and to as yet uncultured bacteria of other anaerobic, dechlorinating microbial communities provides strong evidence for a specific community structure. Such bacteria could be used as potential marker organisms, allowing an optimization of the transformation process by monitoring the community structure by rRNAtargeted fluorescence in situ hybridization or quantitative PCR analysis.

\section{METHODS}

Sampling and cultivation. In August 1997 samples were taken from sediment of the River Saale. The sampling site was located in front of a sewer of a propyleneoxideproducing plant (Buna-Werke, Schkopau) near Halle, Germany. Microbial consortia were cultivated anaerobically as sediment batch cultures at $30^{\circ} \mathrm{C}$ in the dark in mineral salt medium (RAMM medium; Shelton \& Tiedje, 1984) containing DCP $\left(3 \mathrm{mg} \mathrm{l}^{-1}\right)$ and methanol $\left(50 \mathrm{mg}^{-1}\right)$ until a stable dechlorination rate was reached. One of the dechlorinating batch cultures was immobilized subsequently on polyurethane foam cubes (78 d incubation; 100 cubes, each $1 \mathrm{~cm}^{3}$ ) and transferred into a 51 fluidized bed bioreactor made of stainless steel. The reactor was supplied continuously with RAMM medium containing DCP $\left(7 \mathrm{mg} \mathrm{l}^{-1}\right)$ and methanol $\left(50 \mathrm{mg} \mathrm{l}^{-1}\right)$. Transformation of DCP to propene was analysed by head space GC once per day. Until the first sample was taken, the reactor was operated for 3 months under stable conditions $(\mathrm{pH} 6.2$; redox potential $-378 \mathrm{mV}$ ), transforming about $98.5 \%$ of supplied DCP (retention time, $24 \mathrm{~h}$ ).

DNA extraction and purification. Community DNA was extracted from a single foam cube removed from the bioreactor 3 months after start-up. Cell lysis was achieved by a combined treatment using lysozyme, proteinase $\mathrm{K}$, SDS and several freeze-thaw cycles, according to von Wintzingerode et al. (1999). After phenol/chloroform extraction, nucleic acids were ethanol-precipitated and dissolved in Tris/EDTA buffer. To pre-purify DNA, one gel filtration step with Microspin S-300 HR columns (Pharmacia Biotech) was performed. PCR inhibitors and fragmented DNA were removed from high-molecular-mass DNA by preparative agarose gel electrophoresis (Liesack \& Stackebrandt, 1992) using the QIAquick gel extraction kit (Qiagen).

Amplification, cloning and sequence determination of $16 \mathrm{~S}$ rDNA. Purified DNA ( $2 \mu \mathrm{l})$ was used for PCR amplification in a total volume of $50 \mu \mathrm{l}(2 \mathrm{mM} \mathrm{MgCl})_{2}$. DNA was heated initially to $98^{\circ} \mathrm{C}$ for $3 \mathrm{~min}$, then cooled to $93{ }^{\circ} \mathrm{C}$ and $2.5 \mathrm{U}$ AmpliTaq polymerase (Perkin-Elmer) was added. Each of the 28 amplification cycles included denaturation at $93{ }^{\circ} \mathrm{C}$ for $1 \mathrm{~min}$, primer annealing at $53^{\circ} \mathrm{C}$ for $1 \mathrm{~min}$ and extension at $72{ }^{\circ} \mathrm{C}$ for $5 \mathrm{~min}$. Cycling was followed by a final extension step at $72{ }^{\circ} \mathrm{C}$ for $7 \mathrm{~min}$. Amplification with Bacteria-specific forward primer TPU1 (5'-AGAGTTTGATCMTGGCTCAG-3'; Escherichia coli positions 8-27) and reverse primer RTU8 (5'-AAGGAGGTGATCCANCCRCA-3'; E. coli positions 1522-1541) resulted in fragments of about $1500 \mathrm{bp}$. The amplicons were purified using the QIAquick gel extraction kit and ligated subsequently into vector pCR2.1 of the TA cloning kit (Invitrogen). E. coli TOP10F cells were transformed according to the manufacturer's instructions. Recombinant plasmids containing 16S rDNA inserts were extracted by an alkaline lysis procedure using the Amersham Pharmacia GFX Plasmid Preparation Kit. Inserts were PCR-amplified from plasmid DNA using insert-flanking M13 primers. PCR products were purified on a silica matrix (Boyle \& Lew, 1995) and used as templates for direct cycle sequencing with the Thermo Sequenase Fluorescent Labelled Primer Cycle Sequencing Kit (Amersham Pharmacia) using fluorescent-dye-labelled universal M13 primers and different internal primers for sequencing of $16 \mathrm{~S}$ rDNA inserts. Sequencing products were separated and detected on an automated LI-COR DNA 4000L sequencer (MWG).

Phylogenetic analysis. Initial sequence comparison with current $16 \mathrm{~S}$ rDNA databases was done with the FASTA and gapped BLASTN search tool of the HUSAR software package (DKFZ, Heidelberg, Germany). Alignment and phylogenetic analysis of sequence data were performed by using the corresponding tools of the ARB software package (http:// www.mikro.biologie.tu-muenchen.de/pub/ARB/documentation/ARB.ps). The phylogenetic tree shown in Fig. 1 was constructed from 822 positions by applying the neighbour-joining method (Saitou \& Nei, 1987) with 1000 bootstrap resamplings and the Jukes \& Cantor (1969) correction. A consensus mask omitting non-overlapping sequence parts was generated with the ARB program prior to phylogenetic analysis. Additionally, a phylogenetic tree was generated by applying the PHYLIP-parsimony method to verify branching points supported by low bootstrap values. The CHECK-CHIMERA tool (Larsen et al., 1993) was used to search for chimaeric sequences.

Dot blot hybridization of recombinant clones. The approach described by von Wintzingerode et al. (1999), based on hybridization with digoxigenin (DIG)-labelled 16S rDNA fragments, allowed rapid screening of the gene library. Briefly, DIG-labelled rDNA fragments of analysed single clones were generated by nested PCR with primers TPU1 and RTU2 (5'-TGCCTCCCGTAGGAGTYTGG-3'; $E$. coli positions 334-353) from full-length 16S rDNA clone inserts, previously PCR-amplified from plasmid DNA using primers M13( -40$) \mathrm{F}$ and M13 $(-24) \mathrm{R}$. For hybridization, plasmid DNA was heat-denatured, spotted onto a positively charged nylon membrane (Roche Diagnostics) and fixed by UV cross-linking ( 3 min each side, $10 \mathrm{~J} \mathrm{~cm}^{-2}$ ). All hybridization experiments were done with the DIG hybridization system (Boehringer Mannheim), according to the manufacturer's instructions. Hybridization was done in standard hybridization buffer with $50 \%$ formamide at $62^{\circ} \mathrm{C}$ for $4 \mathrm{~h}$, followed by two washing steps with $0 \cdot 1 \times \mathrm{SSC}$ containing $0 \cdot 1 \% \mathrm{SDS}$ at $68^{\circ} \mathrm{C}$ for $25 \mathrm{~min}$ each. 


\section{RESULTS}

The 16S rDNA clone library was designated SHA (Saale, Halle, library A). First, the library was screened with four DIG-labelled polynucleotide probes derived from frequently appearing rDNA clone sequences described previously for another reductively dechlorinating freshwater consortium (von Wintzingerode et al., 1999). Hybridization with 16S rDNA fragments of clone SJA-19 led to positive results. For further analysis, randomly chosen SHA clones were sequenced. Eight of these SHA clones revealed high levels of similarity $(\geqslant 93 \cdot 2 \%)$ to either WCHA, WCHB, WsCH and WFeA clones (Dojka et al., 1998) or SJA clones (von Wintzingerode et al., 1999). These sequence types have been found previously in habitats contaminated with different chlorinated compounds. Therefore, DIG-labelled polynucleotide probes were generated from these eight clones (marked by an asterisk in Table 1) to determine

Table 1. Sequence type distribution found within the 16S rRNA gene library obtained from the DCPtransforming bioreactor

Clones SJA have been reported by von Wintzingerode et al. (1999); clones WCHA, WCHB, WsCH, WFeA have been reported by Dojka et al. (1998). Inserts of clones marked by an asterisk $(*)$ were used as templates to generate DIGlabelled polynucleotide probes for dot blot hybridization.

\begin{tabular}{|c|c|c|c|c|}
\hline $\begin{array}{l}\text { Clone } \\
\text { family }\end{array}$ & $\begin{array}{l}\text { No. of } \\
\text { clones }\end{array}$ & $\begin{array}{l}\text { Database match } \\
(\geqslant 92 \% \text { identity })\end{array}$ & $\begin{array}{l}\text { Similarity } \\
(\%)\end{array}$ & Cluster \\
\hline \multicolumn{5}{|c|}{ Proteobacteria $(\delta)$} \\
\hline SHA-207 & $7 \quad 1$ & SJA-162 & $97 \cdot 9$ & SHA-I \\
\hline SHA-22* & 3 & WsCH54 & $96 \cdot 3$ & SHA-I \\
\hline \multicolumn{5}{|c|}{ Holophaga/Acidobacterium } \\
\hline SHA-18* & 1 & SJA-149 & $93 \cdot 2$ & \\
\hline \multicolumn{5}{|c|}{ Low $\mathrm{G}+\mathrm{C}$ Gram-positives } \\
\hline SHA-67* & 1 & SJA-19 & $99 \cdot 2$ & SHA-IV \\
\hline SHA-61* & 4 & WsCH5 & $96 \cdot 1$ & SHA-V \\
\hline SHA-219 & 1 & WsCH5 & $97 \cdot 2$ & SHA-V \\
\hline SHA-33 & 4 & WsCH5 & $95 \cdot 1$ & SHA-V \\
\hline \multicolumn{5}{|c|}{ Green non-sulfur related cluster } \\
\hline SHA-56 & 4 & WCHB1-43 & $97 \cdot 9$ & SHA-II \\
\hline SHA-24* & 1 & WCHB1-43 & $97 \cdot 9$ & SHA-II \\
\hline SHA-300 & 2 & SJA-108 & $93 \cdot 6$ & SHA-II \\
\hline SHA-28* & 1 & SJA-58 & $94 \cdot 5$ & \\
\hline SHA-105 & 3 & SJA-108 & $92 \cdot 2$ & \\
\hline SHA-53 & 1 & SJA-61 & $96 \cdot 5$ & \\
\hline SHA-3 & 1 & SJA-15 & $97 \cdot 2$ & SHA-III \\
\hline SHA-21* & 9 & SJA-51 & $93 \cdot 6$ & SHA-III \\
\hline \multicolumn{5}{|c|}{ Division level cluster OP8 } \\
\hline SHA-89 & 3 & WFeA1-59 & $94 \cdot 2$ & \\
\hline \multicolumn{5}{|c|}{ Cytophagales } \\
\hline SHA-54 & 1 & WCHA1-01 & $96 \cdot 7$ & SHA-VI \\
\hline SHA-38 & 2 & WCHA1-01 & $96 \cdot 1$ & SHA-VI \\
\hline SHA-25* & 1 & WCHA1-01 & $96 \cdot 3$ & SHA-VI \\
\hline SHA-7 & 1 & WCHB1-29 & $93 \cdot 4$ & \\
\hline
\end{tabular}

their distribution within a total of 300 clones of the SHA clone library by further dot blot hybridization. All SHA clones giving positive hybridization results were sequenced (550-1500 bp). The analysis revealed that a subset of 45 clones showed the highest levels of similarity $(>92 \%)$ to the rDNA sequences retrieved from the dechlorinating consortia mentioned above (Dojka et al., 1998; von Wintzingerode et al., 1999). Based on a sequence similarity of $\geqslant 97 \%$ these 45 clones could be grouped into 20 SHA clone families, which were named after the representative full-length rDNA sequence. No sequence was found to be chimaeric.

Fig. 1 shows the phylogenetic relationships of 20 representative full-length SHA sequences to their most closely related $16 \mathrm{~S}$ rDNA sequences within the domain Bacteria. Based on a sequence similarity $\geqslant 92 \%$, suggesting a close taxonomic relationship, 14 clone families were grouped into six distinct monophyletic bacterial clusters termed SHA-I to -VI (Fig. 1). Each cluster contained at least three sequence families. Four of these clusters comprised exclusively 16S rDNA sequences obtained from reductively dechlorinating freshwater consortia (Dojka et al., 1998; von Wintzingerode et al., 1999; this study), whereas two clusters (SHA-IV and -VI) contained an additional three sequences found also in non-dechlorinating biotopes (SHA-IV, Syntrophobotulus glycolicus; SHAVI, clone LD21, Cytophaga sp. strain BD1-16). Clusters SHA-I to -VI were clearly separated from phylogenetically related $16 \mathrm{~S}$ rDNA sequences derived from both non-reductively dechlorinating freshwater habitats and reductively dechlorinating marine habitats as indicated by sequence divergence of up to $12 \%$ to the phylogenetically most closely related neighbours. The six SHA clone families which did not fall into clusters SHA-I to -VI (SHA-18, -89, -28, -105, -53 and -7 ) exhibited at least $9 \%$ variation to the next most closely related sequences found in other habitats. Within cluster SHA-IV, clone SHA-67 exhibited $97.9 \%$ similarity to Dehalobacter restrictus (Holliger et al., 1998). Dehalobacter restrictus and Dehalobacter sp. strain TEA (Wild et al., 1996) couple anaerobic growth to reductive dechlorination of tetrachloroethene and trichloroethene. Furthermore, SHA-67 was closely related to rDNA sequence SJA-19, which was derived from an anaerobic trichlorobenzene-dechlorinating consortium (von Wintzingerode et al., 1999). Both rDNA sequences shared a nearly identical insertion between positions 75 and 84 (E. coli 16S rRNA numbering).

\section{DISCUSSION}

A large variety of different chlorinated compounds, used mostly as intermediates for chemical synthesis, have been developed by the chemical industry. In general, halogenated compounds are considered to be toxic molecules exhibiting long half-lives (Vogel et al., 1987; Hileman, 1993). In anaerobic environments, 


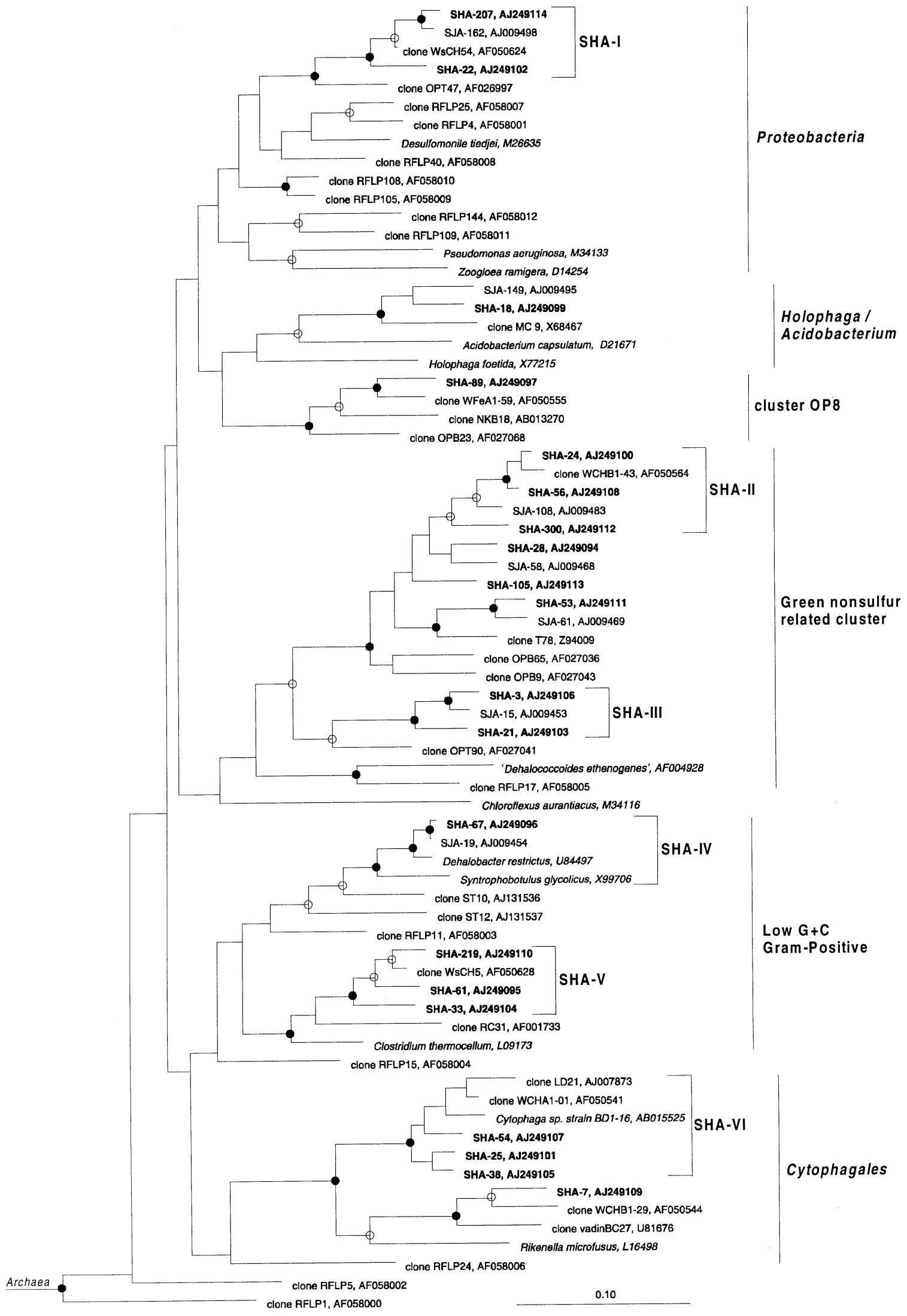

Fig. 1. Phylogenetic relationships of 20 representative full-length SHA sequences obtained from the DCP-dechlorinating bioreactor consortium to $16 \mathrm{~S}$ rDNA sequences obtained from anaerobic, dechlorinating freshwater habitats [sequence prefixes WsCH, WCHA, WFeA and WCHB (Dojka et al., 1998), and SJA (von Wintzingerode et al., 1999)] and anaerobic, 
microbial dehalogenation of halogenated compounds is generally initiated via the reductive route (Suflita $e t$ al., 1982), defined by removal of a halogen substituent from a given molecule with concurrent addition of electrons (Mohn \& Tiedje, 1992). The mixed anaerobic bioreactor culture analysed in this study is capable of dechlorinating DCP to propene by reductive dechlorination. The micro-organisms responsible for reductive dechlorination of DCP have not yet been obtained in pure culture, as is the case for many other chlorinated compounds. This is in contrast to the great number of complex environmental microbiota capable of reductive dechlorination. For technical purposes, i.e. large-scale bioremediation of contaminated aquifers and waste water streams, the application of these complex consortia may represent a promising technology as shown by several experiments using laboratory-scale bioreactors (Hauck et al., 1999; Zou et al., 1999). However, due to the unknown community structure these consortia have been treated as 'black boxes' in the past and a direct optimization of microbial biodegradation has been hampered. One strategy which allows a more optimized control of bioremediation processes is the continuous monitoring of indicator organisms (Power et al., 1998; Stapleton et al., 1998; Brockman, 1995). The aim of our study was to define groups of organisms which exclusively occur in reductively dechlorinating consortia by comparing recently published $16 \mathrm{~S}$ rDNA sequences retrieved from dechlorinating marine and freshwater consortia. These organisms might serve as indicator organisms for the anaerobic, reductive dechlorination of chlorinated compounds.

The first 16S rDNA-based determination of microbial diversity of a reductively dechlorinating consortium was published by Dojka et al. (1998). The authors investigated the microbial diversity in a hydrocarbonand chlorinated-solvent-contaminated aquifer undergoing intrinsic bioremediation. They analysed rDNA clones obtained from samples of the methanogenic, methanogenic-sulfate-reducing and iron- or sulfatereducing zones (WCHA, WCHB, WsCH, WFeA clones). The majority of their bacterial 16S rDNA sequences $(70 \%)$ were phylogenetically associated with recognized bacterial divisions, mainly the green non-sulfur-related cluster, the low G+C Grampositives and the Proteobacteria. Approximately $20 \%$ of the sequence types were affiliated with four division level clusters from a Yellowstone hot spring (OP5, OP8, OP10 and OP11) (Hugenholtz et al., 1998). The remaining $16 \mathrm{~S}$ rDNA sequences $(10 \%)$ suggested the existence of six novel bacterial divisions (WS1-6) (Dojka et al., 1998). In a second study, von
Wintzingerode et al. (1999) investigated the microbial diversity of an anaerobic, trichlorobenzenedechlorinating microbial consortium derived from river sediment. Again, samples were taken from the River Saale, but the sampling site was located near Jena, approximately $200 \mathrm{~km}$ upstream from Halle. Several of the SJA sequences obtained were affiliated with the green non-sulfur related cluster, the Proteobacteria, the division level cluster OP10 (Hugenholtz et $a l ., 1998)$ and the spirochaetes and were closely related to rDNA sequences from the contaminated aquifer (Dojka et al., 1998). In both studies, archaeal rDNA clone libraries were dominated by clone sequences nearly identical to Methanosaeta concilii.

In our study, analysing an anaerobic DCPdechlorinating microbial consortium, at least 20 clone families within the SHA clone library were found to be phylogenetically most closely related to $16 \mathrm{~S}$ rDNA sequences retrieved from the above-mentioned dechlorinating freshwater habitats. Six well separated clusters of closely related sequences were defined, which nearly exclusively comprised rDNA sequences from dechlorinating freshwater habitats. Within cluster SHA-IV, clone families SHA-67 and SJA-19 shared sequence similarities $>97 \%$ to Dehalobacter restrictus (Holliger et al., 1998) or Dehalobacter sp. strain TEA (Wild et al., 1996), respectively. Both isolates are capable of reductive dechlorination of tri- and tetrachloroethene. Our findings indicate the presence of novel members of the genus Dehalobacter. Since known members of that genus share the same dechlorinating phenotype, it is reasonable to assume that as yet uncultured Dehalobacter spp. may contribute to the reductive dechlorination of DCP in the bioreactor described here.

In contrast to reductively dechlorinating consortia derived from freshwater habitats, the composition of corresponding consortia derived from marine habitats is different. A comparative $16 \mathrm{~S}$ rDNA sequence analysis of a marine anaerobic microbial community degrading PCB by reductive PCB ortho-dechlorination (Pulliam Holoman et al., 1998) revealed 16 predominant clone sequences (RFLP clones; Fig. 1), which were phylogenetically distant from clone sequences found in studies on reductively dechlorinating freshwater microbiota (Fig. 1). In a further study, Kengen et al. (1999) examined anaerobic enrichment cultures derived from polluted harbour sediments that reductively dechlorinate tetrachloroethene. Molecular analysis of these cultures indicated the presence of two dominant sequence types, both belonging to the low $\mathrm{G}+\mathrm{C}$ Gram-positives (ST clones; Fig. 1). Highest similarities were found to the halorespiring bacterium

dechlorinating marine habitats [sequence prefixes ST (Kengen et al., 1999) and RFLP (Pulliam Holoman et al., 1998)]. Clusters SHA-I to - $\mathrm{VI}$ comprise nearly exclusively rDNA sequences obtained from anaerobic, dechlorinating freshwater habitats. Methanosaeta concilii (X16932) and Thermoplasma acidophilum (M20822) were used as an outgroup. Branching points were supported by bootstrap values $(0,75 \% ; 0,50-74 \%)$. Branching points without circles were not resolved (bootstrap values $<50 \%$ ). The scale bar represents $10 \%$ sequence divergence. 
Table 2. Comparison of $16 \mathrm{~S}$ rDNA clone libraries obtained from habitats undergoing reductive dechlorination

\begin{tabular}{|c|c|c|c|c|c|}
\hline Habitat & Dehalogenation compounds & Cell lysis procedure & $\begin{array}{l}\text { Cloning } \\
\text { system }\end{array}$ & $\begin{array}{l}\text { Eubacterial } \\
\text { PCR primers }\end{array}$ & Reference \\
\hline $\begin{array}{l}\text { River sediment, } \\
\text { bioreactor }\end{array}$ & $1,2-\mathrm{DCP}$ & $\begin{array}{l}\text { Enzymic, freeze-thaw, } \\
\text { detergent }\end{array}$ & TA cloning & $27 \mathrm{f}-1522 \mathrm{r}$ & This study \\
\hline $\begin{array}{l}\text { River sediment, } \\
\text { bioreactor }\end{array}$ & Trichlorobenzene & $\begin{array}{l}\text { Enzymic, freeze-thaw, } \\
\text { detergent }\end{array}$ & $\begin{array}{l}\text { LIC or TA } \\
\text { cloning }\end{array}$ & $27 \mathrm{f}-1522 \mathrm{r}$ & $\begin{array}{l}\text { von Wintzingerode } \\
\text { et al. (1999) }\end{array}$ \\
\hline Aquifer, ground & $\begin{array}{l}\text { Different hydrocarbons and } \\
\text { chlorinated solvents }\end{array}$ & $\begin{array}{l}\text { Bead beater, enzymic, } \\
\text { detergent }\end{array}$ & TA cloning & $\begin{array}{r}27 \mathrm{f}-1492 \mathrm{r} \\
533 \mathrm{f}-1492 \mathrm{r}\end{array}$ & Dojka et al. (1998) \\
\hline Marine sediment & 2,3,5,6-Tetrachlorobiphenyl & Bead beater, detergent & TA cloning & $519 \mathrm{f}-1406 \mathrm{r}$ & $\begin{array}{l}\text { Pulliam Holoman } \\
\text { et al. (1998) }\end{array}$ \\
\hline Marine sediment & Tetrachloroethene & $\begin{array}{l}\text { Guanidinium thiocyanate, } \\
\text { bead beater }\end{array}$ & TA cloning & $8 \mathrm{f}-1512 \mathrm{r}$ & Kengen et al. (1999) \\
\hline
\end{tabular}

Dehalobacter restrictus $(90 \%)$ and to members of the genus Desulfotomaculum (86\%). Compared to $97.7 \%$ similarity found for clone SHA-67, these low sequence similarities indicate again that marine dechlorinating consortia reveal a different species composition to dechlorinating freshwater consortia.

However, it should be taken into account that comparison of rDNA clone libraries obtained from different habitats under different experimental conditions is limited (Head et al., 1998). Bias can be introduced at various stages in the protocol, particularly during cell lysis, PCR amplification and cloning as reviewed by von Wintzingerode et al. (1997). Therefore, differences in experimental conditions regarding the habitat, the location of sample collection, cell lysis, cloning procedures and PCR primers used have been compiled (Table 2). Different cell lysis procedures and PCR conditions applied by von Wintzingerode et al. (1999) and in this study, but not in the work of Dojka et al. (1998), did not blur our main conclusion that a significant number of rDNA sequences of dechlorinating freshwater habitats were phylogenetically closely related, suggesting a similar population under comparable physiological conditions. In contrast, similar cell lysis and PCR protocols used by Pulliam Holoman et al. (1998) for marine habitats or by Dojka et al. (1998) for freshwater consortia did not reveal rDNA clone libraries of similar composition, indicating an overall low impact of the experimental conditions.

In conclusion the retrieval of $16 \mathrm{~S}$ rDNA sequences closely related to those of cultivated and as yet uncultured bacteria within different anaerobic dechlorinating microbial communities strongly suggests a specific community structure for reductively dechlorinating freshwater habitats. Quantitative studies using primers or probes specific for the SHA clusters and clone families described in this study are currently under way to test our hypothesis on the usefulness of indicator organisms for reductive dechlorination to monitor the efficiency of bioremediation processes.

\section{ACKNOWLEDGEMENTS}

This work was supported by grants from the Deutsche Forschungsgemeinschaft (Sfb 193/D6-YE1 to U.B.G. and Sfb 193/D7 to W.H.).

\section{REFERENCES}

Boyle, J. S. \& Lew, A. M. (1995). An inexpensive alternative to glassmilk for DNA purification. Trends Genetics 11, 8.

Brockman, F. J. (1995). Nucleic-acid-based methods for monitoring the performance of in situ bioremediation. Mol Ecol 4, 567-578.

Dojka, M. A., Hugenholtz, P., Haack, S. K. \& Pace, N. R. (1998). Microbial diversity in a hydrocarbon- and chlorinated-solventcontaminated aquifer undergoing intrinsic bioremediation. Appl Environ Microbiol 64, 3869-3877.

Hauck, R. \& Hegemann, W. (1999). Untersuchungen zum mikrobiellen Abbau von 1,2-Dichlorpropan im Wirbelbettreaktor. gwf Wasser/Abwasser 140, 843-851.

Head, I. M., Saunders, J. R. \& Pickup, R. W. (1998). Microbial evolution, diversity, and ecology: a decade of ribosomal RNA analysis of uncultivated microorganisms. Microb Ecol 35, 1-21.

Hegemann, W., Rotard, W. \& Hauck, R. (1998). Mikrobieller Abbau von chlorierten C3-Verbindungen und Analyse dieser Verbindungen und ihrer Metabolite. In Technische Universität Berlin, Sonderforschungsbereich 193, Biologische Behandlung industrieller und gewerblicher Abwässer, Zwischenbericht, June 1996-June 1998, pp. 217-226. Berlin: Technische Universität Berlin.

Hileman, B. (1993). Concerns broaden over chloride and chlorinated hydrocarbons. Chem Eng News 71, 11-20.

Holliger, C., Hahn, D., Harmsen, H. J. M., Ludwig, W., Schumacher, W., Tindall, B., Vazques, F., Weiss, N. \& Zehnder, A. J. B. (1998). Dehalobacter restrictus gen. nov. and sp. nov., a strictly anaerobic bacterium that reductively dechlorinates tetra- and trichloroethene in an anaerobic respiration. Arch Microbiol 169, 313-321.

Hugenholtz, P., Pitulle, C., Hershberger, K. L. \& Pace, N. R. (1998). Novel division level bacterial diversity in a Yellowstone hot spring. J Bacteriol 180, 366-376.

Jukes, T. H. \& Cantor, C. R. (1969). Evolution of protein molecules. In Mammalian Protein Metabolism, pp. 21-132. Edited by H. N. Munro. New York: Academic Press. 
Kengen, S. W. M., Breidenbach, C. G., Felske, A., Stams, A. J. M., Schraa, G. \& de Vos, W. M. (1999). Reductive dechlorination of tetrachloroethene to cis-1,2-dichloroethene by a thermophilic anaerobic enrichment culture. Appl Environ Microbiol 65, 2312-2316.

Larsen, N., Olsen, G. J., Maidak, B. L., McCaughey, M. J., Overbeck, R., Macke, T. J., Marsh, T. L. \& Woese, C. R. (1993). The ribosomal database project. Nucleic Acids Res 21, 3021-3023.

Liesack, W. \& Stackebrandt, E. (1992). Occurence of novel groups of the domain Bacteria as revealed by analysis of genetic material from an Australian terrestrial environment. J Bacteriol 174, 5072-5078.

Löffler, F. E., Champine, J. E., Ritalahti, K. M., Sprague, S. J. \& Tiedje, J. M. (1997). Complete reductive dechlorination of 1,2dichloropropane by anaerobic bacteria. Appl Environ Microbiol 63, 2870-2875.

Mohn, W. W. \& Tiedje, J. M. (1992). Microbial reductive dechlorination. Microbiol Rev 56, 482-507.

Oldenhuis, R., Vink, R. L., Janssen, D. \& Witholt, B. (1989). Degradation of chlorinated aliphatic hydrocarbons by Methylosinus trichosporium $O B 3 B$ expressing soluble methane monooxygenase. Appl Environ Microbiol 55, 2819-2826.

Power, M., van der Meer, J. R., Tchelet, R., Egli, T. \& Eggen, R. (1998). Molecular-based methods can contribute to assessments of toxilogical risks and bioremediation strategies. $J$ Microbiol Methods 32, 107-119.

Pulliam Holoman, T. R., Elberson, M. A., Cutter, L. A., May, H. D. \& Sowers, K. R. (1998). Characterization of a defined 2,3,5,6tetrachlorobiphenyl-ortho-dechlorinating microbial community by comparative sequence analysis of genes coding for 16S rRNA. Appl Environ Microbiol 64, 3359-3367.

Rasche, M. E., Hyman, M. R. \& Arp, D. J. (1990). Biodegradation of halogenated hydrocarbon fumigants by nitrifying bacteria. Appl Environ Microbiol 56, 2568-2571.
Saitou, N. \& Nei, M. (1987). The neighbor-joining method: a new method for reconstructing phylogenetic trees. Mol Biol Evol 4, 406-425.

Shelton, D. R. \& Tiedje, J. M. (1984). General method for determining anaerobic biodegradation potential. Appl Environ Microbiol 47, 850-857.

Stapleton, R. D., Ripp, S., Jimenez, L., Cheol-Koh, S., Fleming, J. T., Gregory, I. R. \& Sayler, G. S. (1998). Nucleic acid analytical approaches in bioremediation: site assessment and characterization. J Microbiol Methods 32, 165-178.

Suflita, J. M., Horwitz, A., Shelton, D. R. \& Tiedje, J. M. (1982). Dehalogenation: A novel pathway for the anaerobic biodegradation of haloaromatic compounds. Science 218, 1115-1116.

Vandenbergh, P. A. \& Kunka, B. S. (1988). Metabolism of volatile chlorinated aliphatic hydrocarbons by Pseudomonas fluorescens. Appl Environ Microbiol 54, 2578-2579.

Vogel, T. M., Criddle, C. S. \& McCarty, P. L. (1987). Transformation of halogenated aliphatic compounds. Environ Sci Technol 21, 722-736.

Wild, A., Hermann, R. \& Leisinger, T. (1996). Isolation of an anaerobic bacterium which reductively dechlorinates tetrachloroethene and trichloroethene. Biodegradation 7, 507-511.

von Wintzingerode, F., Göbel, U. B. \& Stackebrandt, E. (1997). Determination of microbial diversity in environmental samples: pitfalls of PCR-based rRNA analysis. FEMS Microbiol Rev 21, 213-229.

von Wintzingerode, F., Selent, B., Hegemann, W. \& Göbel, U. B. (1999). Phylogenetic analysis of an anaerobic, trichlorobenzenetransforming microbial consortium. Appl Environ Microbiol 65, 283-286.

Zou, S., Anders, K. M. \& Ferguson, J. F. (1999). Pentachlorophenol dechlorination in fluidized-bed reactors under methanogenic conditions. Bioremed J 3, 93-104. 